\title{
Application of Equivalent Numerical Relational Degree for Groundwater Environmental Quality Evaluation in Coal Mine
}

\author{
Fanxiu Li \\ College of Chemical and Environmental Engineering, \\ Yangtze University \\ Jingzhou Hubei, China \\ lifanxiu@qq.com
}

\author{
Wenmin Gao \\ Oilfield Thermal Power Plant of Daqing Oilfield Power \\ Group, Daqing Oilfield \\ Daqing Heilongjiang, China \\ dqgwm@163.com
}

\begin{abstract}
- a general methodology for equivalent numerical relational degree evaluation is developed and illustrated with a case study of groundwater status assessment for Sang Shuping coal mine. The results of the assessment are in concordance with other evaluation methods. Compared with the other evaluation method, this model is perfect, the evaluating result is more reasonable and its resolving power is higher. Thus, a simple and effective method is provided for groundwater quality evaluation.
\end{abstract}

Key Words-Equivalent numerical relational degree (ENRD), groundwater quality evaluation, coal mine.

\section{INTRODUCTION}

Groundwater is a valuable resource for water supply, even though it is vulnerable to anthropogenic contamination [1]. Groundwater sources in China have suffered pollution to different extents as the development of industrial and agricultural operations in recent years. The quality of water sources is directly related to various problems like economic development and city construction, peoples' living standards and environmental protection. Hence, evaluation of groundwater quality is a necessary and immediate task for present and future groundwater quality management [2].

There are many methods on groundwater quality assessment at present, such as integrated index assessment, grey relational evaluation method, fuzzy mathematics method, attribute recognition model and the matter-element analysis method etc. These evaluation methods had their advantages, but also frequently encountered some problems in its application. Fuzzy mathematics can model the state of water quality very well, but much information can easily be missed. The information utilization and accuracy of grey theory have improved, but the evaluated results are of low resolution and sometimes do not coincide with actual data [3]. The merit of Deng's grey relational degree is its simplicity in computation. However, there are some disadvantages in this formula. The formula is largely affected by the minimal absolute difference or the maximal absolute difference, or the distinguishing rate between the sequences being compared. The grey relational degree of a sequence depends on the characteristics of other sequences being compared, too and therefore it could change substantially when the number of sequences to be compared changes [4]. The relational degree could thus be very fluctuating due to slight changes in the compared sequences. Evaluation results of the attribute recognition model and the matter-element analysis method were affected by random errors of sample, these two methods have some limitations. Therefore, it is important that the existing groundwater quality evaluation methods are complemented and further researched.

In this paper, we attempt to develop a new approach to groundwater quality assessment for the framework based on equivalent numerical relational degree (ENRD). The proposed equivalent numerical relational degree model displays its advantage of simplicity and effectiveness in our case study.

\section{MethodOLOGY}

Equivalent numerical relational degree (ENRD) is considered to be an analysis of the geometric proximity between different discrete sequences, a reference sequence and at least one comparison sequence within a system. The proximity is described by the equivalent numerical relational degree, which is regarded as a measure of the similarities of discrete data that can be arranged in a sequential order. A first notion of this idea and examples of its application may be found in Li et al [5]; the basic idea is as follows.

\section{A. Determination of Equivalent Numerical Coefficients}

To determine the relational degree between the reference and comparison sequences, $\mathrm{Li}$ et al constructed a discrete function of the equivalent numerical relational coefficient. Suppose $\mathrm{X}=(\mathrm{X} 1, \mathrm{X} 2, \ldots, \mathrm{Xn})$ and $\mathrm{Y}=(\mathrm{Y} 1, \mathrm{Y} 2, \ldots, \mathrm{Yn})$ $\in R^{n}$ are two sequences. The inequality $X \leq Y$ means $X(k) \leq Y(k)$ for all $k \in\{1,2, \cdots, n\}$. We propose an algorithm for the equivalent numerical relational degree (ENRD) as follows.

Suppose $\mathrm{X}$ is the reference sequence and $\mathrm{Y}$ the comparison sequence. Equivalent numerical relational coefficients are computed as follows: 
$r(k)=\frac{y(k)}{|x(k)-y(k)|+y(k)}$ For each $k=1,2, \ldots, \mathrm{n}$

\section{B. Compute Equivalent Numerical Relational Degree}

When equivalent numerical relational degree (ENRD) evaluation models were used in the field of groundwater quality evaluation, the comprehensive equivalent numerical relational degree of groundwater quality could be obtained by using super-standard multiple weight method. Denote observed values of water quality index by $X_{i}, X_{i}=\left[X_{i}(1), X_{i}(2), \cdots, X_{i}(n)\right], i=1,2, \cdots n$. There are $m$ evaluation criterions and the grade $j$ is $Y_{j}=\left[y_{j}(1), y_{j}(2), \cdots y_{j}(m)\right], j=1,2, \cdots m$, where $n$ is the number of water quality evaluation index, $m$ is the number of evaluation quality criteria. The sample values of the evaluation index constitute the comparison sequence, and the evaluation standards of evaluation index constitute the reference sequence. The equivalent numerical relational degree of every evaluation index can be computed by Eq. namely $r_{i j}(k)=r_{i j}\left(X_{i}, Y_{j}\right), i=1,2, \cdots n, j=1,2, \cdots m$.

Given the weight vector of evaluation index is denoted by $W=\left[\bar{W}_{1}, \bar{W}_{2}, \cdots, \bar{W}_{n}\right]$.

$$
r_{i j}(X, Y)=\sum_{k=1}^{n} \bar{W}_{k} r_{i j}(k)
$$

where $\square \bar{W}(k)$ is weight of index $k, k=1,2, \cdots n$.

\section{Determination of Every Evaluation Index Weight}

Weight plays a key role in the comprehensive evaluation mathematical model, it reflects the position and role of each index in the procedure of comprehensive decision making, and directly influences the result of the comprehensive evaluation. For the same measured data, the low content and high standard allowable concentration largely affect the pollution comparatively. The weight considers two parts equally, one of which is the super-standard extent, and the other is the difference among water quality levels. In the former part, the super-standard of every index at each evaluating object is calculated; the larger the amount of pollution, the greater the weight; in the latter part, differences among levels of water quality standard are taken into consideration. The worse the level, the greater the weight [6].

$$
W_{i}=x_{i} / \bar{Y}_{j}, \bar{Y}_{j}=\frac{1}{m} \sum_{j=1}^{n} Y_{j}
$$

where, $x_{i}$ is the measured value of index $i, \bar{Y}_{j}$ is the arithmetic mean of index $i$ in each grading representative value; $Y_{j}$ is the typical value of index $i$ in each grading standard. In order to make the compositional operation, the weight of each single factor should be normalized as follows:

$\bar{W}_{i}=W_{i} / \sum_{i=1}^{n} W_{i}$

where $W_{i}$ is the normalized weight of the evaluation index $i$.

\section{Calculating of the Grade of Groundwater Quality Status}

Usually, the maximum relational degree is used for groundwater quality evaluation. To avoid causing inaccurate assessment, the eigenvalue $j^{*}$ is adopted to groundwater quality evaluation. For example, $j^{*}=3.7$ means that the evaluated water quality is at a coarse grade of III but biased towards grade IV. More exactly, the water quality is evaluated at a grade of 3.7. The grades of evaluation could be defined as follows [7]:

$$
j^{*}=\frac{\sum_{j=1}^{m} j \cdot \bar{r}_{i j}}{\sum_{j=1}^{m} \bar{r}_{i j}} \text { And } \bar{r}_{i j}=\frac{r_{i j}-\operatorname{Min}\left(r_{i j}\right)}{\operatorname{Max}\left(r_{i j}\right)-\operatorname{Min}\left(r_{i j}\right)}
$$

where, $\operatorname{Max}\left(r_{i j}\right)$ and $\operatorname{Min}\left(r_{i j}\right)$ are the maximum value and minimum value of the $\mathrm{j}$-th relational degree respectively, $r_{i j}$ is the comprehensive relational degree of the $j$-th grade.

\section{CASE STUDY}

Based on characteristics of groundwater environmental quality, total hardness, dissolved solids, $\mathrm{Cl}^{-}$and $\mathrm{SO}_{4}{ }^{2-}$ were chosen as evaluation factors. According to the characters of the groundwater environment and consulted the most widely used standards, new standards were built up that contain four grades as can be seen in Table I . At the same time Table II shows the sample indexes values about ten monitoring points in Sang Shuping coal mine [5]. To examine the feasibility and effectiveness of the model, the suggested method has been applied to groundwater quality assessment.

TABLE I. STANDARDS OF THE GROUNDWATER ENVIRONMENTAL QUALITY

\begin{tabular}{ccccc}
\hline $\begin{array}{c}\text { Total hardness } \\
(\mathrm{mg} / \mathrm{L})\end{array}$ & $\begin{array}{c}\text { Dissolved } \\
\text { solids }(\mathrm{mg} / \mathrm{L})\end{array}$ & $\begin{array}{c}\mathrm{Cl}^{-} \\
(\mathrm{mg} / \mathrm{L})\end{array}$ & $\begin{array}{c}\mathrm{SO}_{4}{ }^{2-} \\
(\mathrm{mg} / \mathrm{L})\end{array}$ & $\begin{array}{c}\text { Water quality } \\
\text { grade }\end{array}$ \\
\hline$<150$ & $<300$ & $<50$ & $<50$ & grade I \\
300 & 500 & 150 & 150 & grade II \\
450 & 1000 & 250 & 250 & grade III \\
500 & 2000 & 350 & 350 & grade IV \\
\hline
\end{tabular}


TABLE II. SURVEYED DATA OF WATER ENVIRONMENTAL QUALITY IN SANG SHUPING COAL MINE.

\begin{tabular}{ccccc}
\hline $\begin{array}{c}\text { Monitoring } \\
\text { points }\end{array}$ & $\begin{array}{c}\text { Total hardness } \\
(\mathrm{mg} / \mathrm{L})\end{array}$ & $\begin{array}{c}\text { Dissolved solids } \\
(\mathrm{mg} / \mathrm{L})\end{array}$ & $\begin{array}{c}\mathrm{Cl}^{-} \\
(\mathrm{mg} / \mathrm{L})\end{array}$ & $\begin{array}{c}\mathrm{SO}_{4}{ }^{2-} \\
(\mathrm{mg} / \mathrm{L})\end{array}$ \\
\hline 1 & 170.15 & 252.00 & 14.72 & 25.24 \\
2 & 164.47 & 250.00 & 12.41 & 36.04 \\
3 & 203.28 & 541.00 & 34.00 & 51.83 \\
4 & 290.26 & 536.64 & 32.37 & 95.00 \\
5 & 600.38 & 965.75 & 76.50 & 416.95 \\
6 & 205.80 & 325.43 & 1.48 & 16.68 \\
7 & 406.50 & 870.00 & 158.20 & 80.00 \\
8 & 594.16 & 1150.00 & 4.43 & 219.59 \\
9 & 657.71 & 1404.00 & 2.66 & 351.44 \\
10 & 701.66 & 1625.00 & 2.66 & 409.31 \\
\hline
\end{tabular}

Take the monitoring point 1 as an example, we put the data of Table I and II into the Eq. (3) and (4), and the weight of the monitoring point 1 is $W=\{0.5111,0.2789,0.0774,0.1326\}$. In a similar way, the weight values for each index of other monitoring points can be obtained.

The observation values of the monitoring point may be represented by the discrete sequences: $X 1=(170.15,252.00$, $14.72,25.24)$. According to the standard, the water quality criteria is defined as follows: $\mathrm{Y} 1$ (grade I $)=(150,300,50,50)$; $\mathrm{Y} 2($ grade II $)=(300,500,150,150)$; Y3 $($ grade III $)=(450,1000$, 250, 250); Y4(grade IV $)=(500,2000,350,350)$. The equivalent numerical relational degree of the evaluation index can be obtained through Eq. (1) and (2). The evaluation grade of every monitoring point may be computed using Eq. (5). The evaluation results were shown in Table III.

TABLE III. COMPARISON OF ENRD WITH OTHER METHODS

\begin{tabular}{ccccc}
\hline $\begin{array}{c}\text { Monitoring } \\
\text { points }\end{array}$ & Grades & ENRD & $\begin{array}{c}\text { grey } \\
\text { clustering[5] }\end{array}$ & $\begin{array}{c}\text { fuzzy } \\
\text { evaluation }\end{array}$ \\
\hline 1 & 1.3500 & I & I & I \\
2 & 1.3188 & I & I & I \\
3 & 1.7873 & II & I & I \\
4 & 2.5366 & II -III & II & II \\
5 & 3.2614 & III & IV & IV \\
6 & 1.5541 & I - II & I & I \\
7 & 2.9712 & III & II & III \\
8 & 3.1704 & III & III & III \\
9 & 3.3095 & III & IV & IV \\
10 & 3.3604 & III & IV & IV \\
\hline
\end{tabular}

It was found from Table III that the results from the proposed model did agree well with the actual situation of samples and from the fuzzy mathematics method and grey clustering method except for the monitoring point 3,9 and 10. However, for the monitoring point 3 , it is found that the number of evaluation in indexes are 4 , in which the number of indexes are total hardness, dissolved solids, $\mathrm{Cl}^{-}$and $\mathrm{SO}_{4}{ }^{2-}$ respectively whose value are coincident with the degree of grade II, grade III, grade I and grade II according to the classification standard. It is obvious that the grade II for the monitoring point 3 much more really reflected the characteristics of water quality. Because in the new method both the difference among water quality level and the proportion of the pollutant over standard are taken into the consideration, the results turn out to be closer to the fact. Compared with the grey clustering method and fuzzy evaluation model, the new method is more comprehensive. On the other hand, grey clustering method and fuzzy evaluation model may emphasize some specific pollutant, so that the final synthetic results may be affected by abnormal values and lose the creditability.

\section{CONCLUSIONS}

Equivalent numerical relational degree evaluation with the super-standard of every index method for weight determination was used to assess the integrated groundwater quality and the result of this method was compared with the typical fuzzy synthetic evaluation, the conclusions are summarized as follows:

(1) Equivalent numerical relational degree (ENRD), as a new uncertainty analyzing method, can combine the dialectical understanding of the problem and the quantitive description of the system together. The results show that the method is effective in groundwater quality evaluation.

(2) The improved super-standard multiple weight method calculates the weight coefficient by the standard value of quality level of monitor, the results can reflect the degree of contribution to subordinate grade of the monitor data of water environment factors accurately. It is closer to the actual result of the weight than the traditional method.

(3) The proposed method is simple in concept and convenient to calculate and feasible for application. The level variable character computed is seen to give a finer grading of the water quality, thus, our numerical results broadly agree to those of other methods.

(4) The results of assessment are satisfactory. The case studies of water status assessment have shown that the ENRD method is effective and reliable, and is provided a science basis for policy decision of groundwater environment management.

\section{REFERENCES}

[1] D. Kaown, Y. Hyun, G. O Bae, C. Whan and K. K. Lee, "Evaluation of spatio-temporal trends of groundwater quality in different land uses using Kendall test," Geosciences Journal, vol 16, No. 1, pp. 65-75, March 2012.

[2] B. Xu and Z. Y. Cai, "Unascertained measure model for water quality evaluation based distinguish weight," Advanced Technology in Teching-Proceedings of the 2009 3rd International Conference on Teaching and Computational Science (WTCS 2009), vol. 116, pp. 213-220, February 2012.

[3] S. Z. Chen, X. J. Wang and X. J. Zhao, "An attribute recognition model based on entropy weight for evaluating the quality of groundwater sources," J China Univ. Mining \& Technol., vol. 18, pp. 72-75, May 2008.

[4] W. C. Ip, B. Q. Hu, H. Wong and J. Xia, "Applications of grey relational method to river environment quality evaluation in 
China," Journal of Hydrology, vol. 379, No. 3-4, pp. 284-290, December 2009.

[5] F. X. Li and W. Chen, "The equivalent numerical method for groundwater environmental quality evaluation in coal mine," Groundwater, vol. 24, No. 4, pp. 218-219, December 2002.

[6] F. X. Li, "Evaluation method quality based on Euclidean distance model with varying weight," 2012 International
Conference on Electric Technology and Civil Engineering, pp.1538-1541, May 2012.

[7] F. X. Li, "Application of five-element connection number in lake eutrophication evaluation," Advanced Materials Research, vol. 183-185, pp. 211-215, March 2011. 